\title{
(6) OPEN ACCESS \\ Characteristics of healthcare organisations struggling to improve quality: results from a systematic review of qualitative studies
}

\author{
Valerie M Vaughn, ${ }^{1,2,3}$ Sanjay Saint, ${ }^{1,2,3}$ Sarah L Krein, ${ }^{1,2,3}$ \\ Jane H Forman, ${ }^{2,3}$ Jennifer Meddings, ${ }^{1,2,3,4}$ Jessica Ameling, ${ }^{1,3}$ \\ Suzanne Winter, ${ }^{1,3}$ Whitney Townsend, ${ }^{5}$ Vineet Chopra ${ }^{1,2,3}$
}

\begin{abstract}
- Additional material is published online only. To view please visit the journal online (http://dx.doi.org/10.1136/ bmjqs-2017-007573).
\end{abstract}

For numbered affiliations see end of article.

\section{Correspondence to}

Dr Valerie M Vaughn, Internal Medicine, University of

Michigan, Ann Arbor, Ml 48109, USA; valmv@umich.edu

Received 3 November 2017 Revised 11 June 2018 Accepted 24 June 2018 Published Online First 25 July 2018

\section{Check for updates}

(c) Author(s) (or their employer(s)) 2019. Re-use permitted under CC BY-NC. No commercial re-use. See rights and permissions. Published by BMJ.

To cite: Vaughn VM, Saint $S$ Krein SL, et al. BMJ Qual Saf 2019;28:74-84.

\begin{abstract}
Background Identifying characteristics associated with struggling healthcare organisations may help inform improvement. Thus, we systematically reviewed the literature to: (1) Identify organisational factors associated with struggling healthcare organisations and (2) Summarise these factors into actionable domains.

Methods Systematic review of qualitative studies that evaluated organisational characteristics of healthcare organisations that were struggling as defined by below-average patient outcomes (eg, mortality) or quality of care metrics (eg, Patient Safety Indicators). Searches were conducted in MEDLINE (via Ovid), EMBASE, Cochrane Library, CINAHL, and Web of Science from database inception through February 8 2018. Qualitative data were analysed using framework-based synthesis and summarised into key domains. Study quality was evaluated using the Critical Appraisal Skills Program tool.

Results Thirty studies (33 articles) from multiple countries and settings (eg, acute care, outpatient) with a diverse range of interviewees (eg, nurses, leadership, staff) were included in the final analysis. Five domains characterised struggling healthcare organisations: poor organisational culture (limited ownership, not collaborative, hierarchical, with disconnected leadership), inadequate infrastructure (limited quality improvement, staffing, information technology or resources), lack of a cohesive mission (mission conflicts with other missions, is externally motivated, poorly defined or promotes mediocrity), system shocks (ie, events such as leadership turnover, new electronic health record system or organisational scandals that detract from daily operations), and dysfunctional external relations with other hospitals, stakeholders, or governing bodies.

Conclusions Struggling healthcare organisations share characteristics that may affect their ability to provide optimal care. Understanding and identifying these characteristics may provide a first step to helping low performers address organisational challenges to improvement.
\end{abstract}

Systematic review registration PROSPERO: CRD42017067367.

\section{INTRODUCTION}

The Institute of Medicine's 2001 report addressing variation in quality of care ${ }^{1}$ spurred strong interest by healthcare organisations and patients to improve quality. ${ }^{2}$ Today, US healthcare quality is publicly reported and linked to reimbursement, providing an impetus for improvement. Some healthcare organisations, however, still have difficulty crossing the quality chasm. ${ }^{3}$ The potential causes of failing to attain quality targets are myriad. For example, resource availability, location and patient case-mix can affect performance. ${ }^{4-8}$ Yet, these factors only partially explain variation in quality. ${ }^{7}$

Studies of top-performing organisations suggest they share common features, including a positive 'organisational culture' (ie, the norms, values and basic assumptions of an organisation) that embraces change. ${ }^{9-11}$ This flexibility may accelerate adoption of patient safety initiatives that improve care. ${ }^{12-16}$ In addition, high performing organisations often have robust patient safety programmes, ${ }^{15} 16$ led by committed individuals who support and respect employees. ${ }^{16}$ While much is known about success in high-performing organisations, little is known about why low performing organisations struggle. Addressing this gap can help organisations most in need identify and overcome barriers.

We thus conducted a systematic review of qualitative studies that evaluated healthcare organisations with below-average performance in patient outcomes or quality of care metrics. Taking advantage of detailed, discovery-oriented data 
contained in qualitative studies, ${ }^{17}$ we performed framework-based thematic synthesis ${ }^{18}$ to: (1) Identify organisational factors associated with struggling healthcare organisations and (2) Summarise these factors into actionable domains that may inform efforts to improve quality.

\section{METHODS}

A research team composed of experts in implementation science, qualitative research methods, patient safety and systematic reviews was convened to determine project design and data throughout the study. We developed and registered a study protocol (PROSPERO: CRD42017067367, available at: http:// www.crd.york.ac.uk/prospero/display_record.asp? $s r c=$ trip\&ID $=C R D 42017067367)$ following the Preferred Reporting Items for Systematic Reviews and Meta-Analyses recommendations. ${ }^{20}$

We focused on qualitative studies-those that use open-ended techniques, such as interviews and non-statistical techniques for analysis ${ }^{17}$ for three reasons. First, qualitative data are useful to evaluate some concepts (such as culture) that can be difficult to measure quantitatively. ${ }^{21}$ Second, qualitative studies allow concepts to be evaluated in context (eg, how do the beliefs and experiences of front-line staff affect implementation?) adding depth to understanding. Finally, rather than having a priori hypotheses, inclusion of qualitative studies allows for inductive generation of themes (summary concepts based on data) to identify novel aspects related to performance. ${ }^{17}$

We sought to specifically identify characteristics and barriers that may impede improvement efforts and/or result in poor patient outcomes at struggling healthcare organisations. Therefore, in contrast to studies of 'positive deviants', we studied such 'negative deviants' to identify unique barriers that may not be present in average or high-performing organisations, thus informing efforts directly applicable to such organisations. $^{22}$

\section{Inclusion criteria}

Qualitative studies were eligible for inclusion if they evaluated organisational or cultural characteristics in the context of struggling healthcare organisations. 'Healthcare organisations' included ambulatory, subacute, acute, emergency or intensive care settings in any private or public institution. We identified a facility as 'struggling' when below-average performance in patient outcomes (eg, mortality) or quality of care (eg, Patient Safety Indicators (PSI-90) Score) was reported. Studies that reported compliance with an intervention or financial performance without associated patient outcomes or quality of care were excluded. Three authors (VV, JA, SW) independently determined eligibility with disagreements resolved through consensus.

\section{Search strategy}

Between November 2016 and February 2018, a medical librarian (WT) performed serial literature searches from database inception through February 82018 in the following databases: MEDLINE (via Ovid), EMBASE, Cochrane Library, CINAHL and Web of Science. Searches designed for each database included controlled vocabulary terms (Medical Subject Headings) when available, combined with keywords to represent concepts such as 'low performer,' 'laggard' (online supplementary appendix). Additional studies of interest were found through hand searches of bibliographies and discussion with content experts.

\section{Data extraction}

Data were extracted from included studies independently and in duplicate by 3 authors (VV, JA, SW) on a template adapted from the Cochrane Collaboration. ${ }^{23}$ Data included definitions for performance, number and role of interviewees, method for sampling (eg, snowball), data collection (eg, interviews) and analysis, and main findings.

We specifically abstracted the following data for analysis: (1) Primary quotes from interviewees (eg, 'I would like to see more collaboration...'-Director of Performance'), ${ }^{24}$ (2) Summary quotes (eg, 'Participants also indicated an inadequate emphasis on learning, ${ }^{24}$ and (3) Author interpretations of study data (eg, 'The lack of congruence between ... mission[s] created tension'. ${ }^{25}$ Author interpretations were collected primarily from the results section of manuscripts, however (consistent with other reviews), ${ }^{16}{ }^{26}$ interpretations from the discussion were abstracted when supported by data. ${ }^{26}$ When studies also included high performers, we abstracted data contrasting these 2 categories.

\section{Creation of domains}

Abstracted data were analysed using framework-based synthesis-a robust method of pragmatically combining themes from qualitative studies. ${ }^{18} 19$ This methodology involved a two-step process. ${ }^{18} 1927$ First, a framework relevant to the study question was identified a priori. Given its comprehensiveness, widespread applicability and focus on systematically assessing organisational context, we chose the Consolidated Framework for Implementation Research (CFIR). ${ }^{9}$ CFIR spans 39 constructs consolidated from implementation frameworks to systematically assess contextual factors that influence practice and change efforts. Using CFIR constructs, we created a codebook for identifying organisational characteristics including CFIR domains such as 'Outer Setting' and 'Process'.' Given that many CFIR constructs are positive or focus on project implementation, not all domains were applicable (eg, 'innovation characteristics') and we modified some domains to the negative (eg, 'leadership engagement' to 'disconnected leadership'; online supplementary 
table 1). Each manuscript underwent line by line coding independently and in duplicate by 3 authors. We paid particular attention to data that contradicted potential underlying assumptions (eg, struggling institutions with exemplary leadership) and report the frequency of supportive versus contradictory references for domains. ${ }^{28}$ All coding was performed using QSR International's NVivo V.11.

The second step of framework-based thematic synthesis involved iteratively updating, modifying, refining and creating codes and definitions to describe emerging concepts. We met weekly to compare independently coded manuscripts for consistency to determine whether codes should be revised, removed or added. This approach encouraged generation of new ideas, while incorporating robust theory from prior research. ${ }^{262729}$ For example, the code 'hierarchical culture' (defined by CFIR as 'clear lines of authority over organisational processes') ${ }^{9}$ remained consistent. Conversely, when ideas emerged that were not related to CFIR constructs, we created novel codes. For example, 'major scandals'-a negative public relations event that detracted from daily operations-emerged inductively.

After aggregating codes into themes, ${ }^{30} 5$ overarching domains that distinguish struggling healthcare organisations were identified. Some codes (eg, mergers) remained as stand-alone themes. Finally, we examined whether representation of domains varied by definition of 'struggling.' For this purpose, definitions included: (1) Overall performance metrics (any global hospital rating, eg, star rating), (2) Composite metrics (combined outcomes from at least two diseases, such as PSI-90), or (3) Disease-specific metrics (included either a single disease or outcome, such as central line-association bloodstream infection (CLABSI) rates).

\section{Quality assessment}

Study risk of bias was assessed using the Critical Appraisal Skills Program (CASP) checklist, ${ }^{31}$ which is recommended by the Cochrane Collaboration for qualitative literature. ${ }^{32}$ The CASP tool consists of 10 questions: 9 addressing quality and 1 addressing 'value' (contribution to existing literature). For studies with multiple publications, risk of bias was assessed for the earliest. Three reviewers (VV, JA, SW) assessed each study independently and in duplicate with disagreements resolved through consensus. In accordance with other qualitative reviews, studies were not excluded or stratified by risk of bias. ${ }^{162633}$ Rather, we assessed relative contribution of low-quality and highquality studies in defining our domains. ${ }^{27}$

\section{RESULTS}

The search yielded 30 unique qualitative studies (33 articles) from various countries (figure 1). ${ }^{2425}{ }^{34-64}$ Studies included adult (12 studies) ${ }^{243435404145474853545764}$ or paediatric (1 study) $)^{63}$ acute-care hospitals, emergency rooms (1 study), ${ }^{39}$ nursing homes (3 studies), ${ }^{25} 5260$ outpatient primary (7 studies) ${ }^{38434449586162}$ or specialty clinics (1 study), ${ }^{51}$ primary health systems (1 study), ${ }^{37}$ accountable care organisations (1 study), ${ }^{36}$ hospital units (2 studies), ${ }^{55} 56$ or residential treatment programmes (1 study), ${ }^{59}$ and a diverse range of study participants, including healthcare employees in administrative, clinical and leadership roles. Study sample sizes ranged from 17 to 194 and all but 1 study ${ }^{50}$ had a high-performing comparator group. Two studies had a mid-performing comparison group. ${ }^{44} 63$ Criteria for defining performance varied: 4 studies used overall performance metrics, ${ }^{36} 46506112$ used composite metrics 253537414352535557 and 14 used disease-specific metrics (online supplementary table 2). ${ }^{4243438-404448495156585963}$

\section{Domains characterising struggling healthcare organisations}

Five domains (figure 2) consistently characterised struggling healthcare organisations, including: (1) Poor organisational culture, (2) Inadequate infrastructure, (3) Lack of a cohesive mission and vision, (4) System shocks and (5) Dysfunctional external relations. Domain definitions, themes, frequency of reporting, contrary findings and representative quotes are reported in table 1.

\section{Poor organisational culture}

All 30 studies described poor organisational culture within struggling healthcare organisations (figure 2) that could be further classified into themes. The most frequent theme, limited involvement and ownership, was found in 27 studies. $^{2425} 34-3840-444648-52$ 55-63 This included lack of established responsibility or consequences (16 studies) ${ }^{24} 253436-38414648-505255-5761$ and front-line employees who lacked a sense of ownership (4 studies) $^{50586061}$ or self-efficacy (3 studies) 24344860 with many interviewees blaming patient factors for failure (9 studies). ${ }^{34} \quad 36 \quad 4048 \quad 50 \quad 58-60 \quad 62$ The second theme, a non-collaborative environment (21 studies), ${ }^{424} 25353638-40424448$ 50-53 55-57 61-63 manifested with employees who: did not feel connected to each other or their institution (8 studies), 425384248526162 operated in silos (7 studies), ${ }^{24253536444855}$ or suffered from low morale (6 studies). ${ }^{25} 50-526162$ The third theme

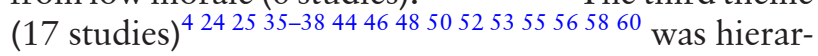
chical orientation ('clear lines of authority of organisational processes'). ${ }^{9}$ Hierarchy was often used to explain why middle managers and champions lacked empowerment ( 3 studies) ${ }^{465060}$ and nurses and staff felt undervalued (10 studies). ${ }^{4} 242536384448505253555658$ Interviewees noted that physician autonomy appeared to trump patient safety (3 studies) $)^{36550}$ and approaches to problems were punitive (7 studies). ${ }^{4242535505560}$ This type of negative hierarchy reportedly resulted in anxiety and fear (5 studies). ${ }^{4} \begin{array}{llllll}25 & 37 & 48 & 50 & \text { The }\end{array}$ final theme involved disconnected leaders (16 

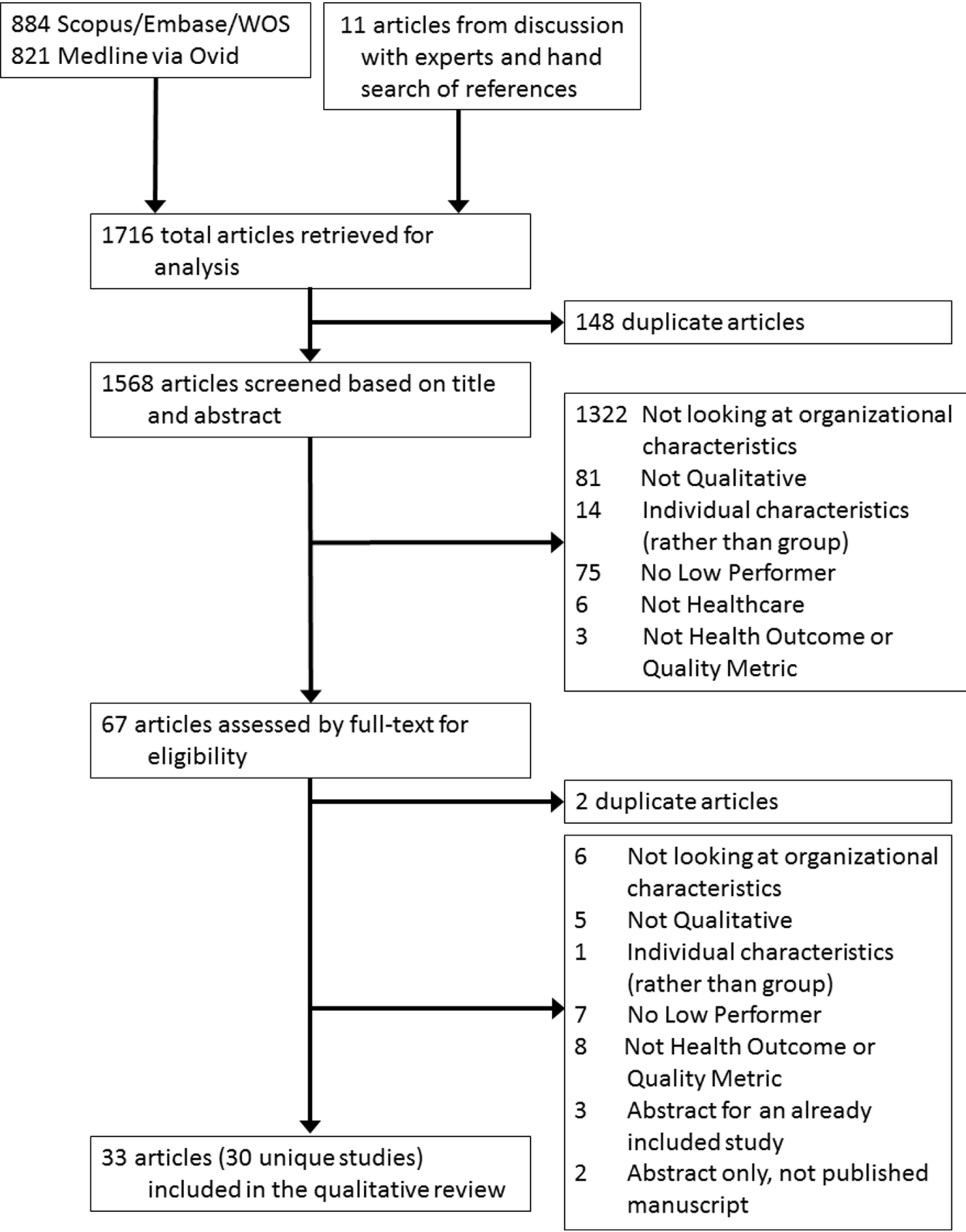

Figure 1 Flow diagram of study selection. WOS, Web of Science.

studies) ${ }^{242536-384041464850525356576162}$ who were blamed for the organisation's poor culture, thus interviewees linked poor leadership to poor culture. Leaders were described as unsupportive (7 studies), ${ }^{37485253576162}$ underdeveloped (3 studies) ${ }^{344157}$ or non-transparent (6 studies). ${ }^{363746505261}$

\section{Inadequate infrastructure}

All but 3 studies ${ }^{52} 5861$ reported inadequate infrastructure in struggling healthcare organisations. Examples included inadequate QI infrastructure and processes (20 studies), ${ }^{4} 24253436-424448-5053 \quad 55-5762$ insufficient staffing or high turnover (18 studies), $42425353638394142444649-5155596062$ poor information technology services $\left(\begin{array}{llll}17 & \text { studies })^{24} & 35-38 & 41-43\end{array}\right.$ $4648-5155576263$ and general lack of resources (15 studies). ${ }^{24} 3637434448-51535960626365$ Despite the emphasis placed on infrastructure in struggling sites, 18 studies $^{4} 2434353739-42485153575860-63$ also reported inadequate infrastructure in high-performing organisations (eg, 'all sites lacked guidelines ... and [had limited staffing] at night'; $;$ ' 'all sites... had inadequate computer facilities's $)^{42}$ or that infrastructure alone appeared insufficient to create high performance: 'The electronic record (EHR) was viewed as a useful tool...but efforts to rely on electronic documentation did not necessarily guarantee improvement'. ${ }^{40}$

\section{Lack of cohesive mission and vision}

Twenty-one of the 30 studies noted that struggling healthcare organisations lacked a cohesive mission or vision. ${ }^{24} 2535363840-43$ 48-505253555658 60-63 Instead, struggling organisations perceived their mission as: (1) conflicting with other stated missions (12 


\begin{tabular}{|c|c|c|c|c|c|}
\hline \multirow{2}{*}{ Domain } & \multirow{2}{*}{ Themes } & \multicolumn{3}{|c|}{$\begin{array}{l}\text { Percent of Studies Referencing Themes, } \\
\text { by Definition of Low Performance }{ }^{1}\end{array}$} & \multirow{2}{*}{ Total, $^{2} n=30$} \\
\hline & & $\begin{array}{c}\text { Overall, } \\
\mathrm{n}=4\end{array}$ & $\begin{array}{c}\text { Composite, } \\
n=12\end{array}$ & $\begin{array}{c}\begin{array}{c}\text { Disease Specific, } \\
n=14\end{array} \\
\end{array}$ & \\
\hline \multirow{4}{*}{$\begin{array}{c}\text { Poor } \\
\text { Organizational } \\
\text { Culture }\end{array}$} & Limited Ownership \& Involvement & $4(100 \%)$ & $11(92 \%)$ & $12(86 \%)$ & $27(90 \%)$ \\
\hline & Not Collaborative & $3(75 \%)$ & $8(67 \%)$ & $10(71 \%)$ & $21(70 \%)$ \\
\hline & Hierarchical & $3(75 \%)$ & $7(58 \%)$ & $7(50 \%)$ & $17(57 \%)$ \\
\hline & Disconnected Leadership & $4(100 \%)$ & $7(58 \%)$ & $5(36 \%)$ & $16(53 \%)$ \\
\hline \multirow{4}{*}{$\begin{array}{l}\text { Inadequate } \\
\text { Infrastructure }\end{array}$} & Minimal Quality Improvement Systems & $2(50 \%)$ & $8(67 \%)$ & $10(71 \%)$ & $20(67 \%)$ \\
\hline & Insufficient Staffing and High Turnover & $3(75 \%)$ & $7(58 \%)$ & $8(57 \%)$ & $18(60 \%)$ \\
\hline & Underdeveloped Information Technology & $3(75 \%)$ & $8(67 \%)$ & $6(43 \%)$ & $17(57 \%)$ \\
\hline & Lack of Resources & $2(50 \%)$ & $6(50 \%)$ & $7(50 \%)$ & $15(50 \%)$ \\
\hline \multirow{4}{*}{$\begin{array}{l}\text { Lack of Cohesive } \\
\text { Mission and Vision }\end{array}$} & Conflicting Missions & $1(25 \%)$ & $6(50 \%)$ & $5(36 \%)$ & $12(40 \%)$ \\
\hline & Externally Motivated Vision & $1(25 \%)$ & $5(42 \%)$ & $3(21 \%)$ & $9(30 \%)$ \\
\hline & Poorly Defined Goals & $2(50 \%)$ & $2(17 \%)$ & $2(14 \%)$ & $6(20 \%)$ \\
\hline & Vision of Mediocrity & 0 & $1(8 \%)$ & $4(29 \%)$ & $5(17 \%)$ \\
\hline \multirow{5}{*}{ System Shocks } & C-suite (or Senior Leadership) Turnover & $2(50 \%)$ & $5(42 \%)$ & $1(7 \%)$ & $8(27 \%)$ \\
\hline & Financial Failure or Severe Difficulties & $1(25 \%)$ & $1(8 \%)$ & $2(14 \%)$ & $4(13 \%)$ \\
\hline & Mergers (or Reorganization) & $3(75 \%)$ & $1(8 \%)$ & 0 & $4(13 \%)$ \\
\hline & New Electronic Health Records & $2(50 \%)$ & $1(8 \%)$ & $1(7 \%)$ & $4(13 \%)$ \\
\hline & Major Scandals (Public Relations Difficulties) & $1(25 \%)$ & 0 & 0 & $1(3 \%)$ \\
\hline \multirow{3}{*}{$\begin{array}{l}\text { Dysfunctional } \\
\text { External } \\
\text { Relationships }\end{array}$} & Limited Collaboration with Other Hospitals & $2(50 \%)$ & $2(17 \%)$ & $1(7 \%)$ & $5(17 \%)$ \\
\hline & Antagonism with Stakeholders & $3(75 \%)$ & $1(8 \%)$ & 0 & $4(13 \%)$ \\
\hline & Strained Relationships with Governing Body & $1(25 \%)$ & $1(8 \%)$ & 0 & $2(7 \%)$ \\
\hline
\end{tabular}

Figure 2 Heat map by percentage of studies referencing each theme. The percentage of studies that included codes for each theme are shown. Studies are separated by method of defining low performance into: (a) overall metrics (eg, star ratings), (b) composite metrics (eg, readmission rates for multiple diseases), or (c) disease-specific metrics (eg, 30-day mortality for acute myocardial infarction)). ${ }^{1}$ Colour scale for studies by method of defining performance: white $=$ no studies, yellow=least studies to red=most studies. ${ }^{2}$ Colour scale for all studies combined: green-least studies to blue-most studies.

studies), ${ }^{253840424850535558606263}$ (2) externally motivated (eg, by finances/penalties, 9 studies), 242535404148505253 (3) poorly defined (6 studies) $)^{253638486162}$ or (4) reflecting a 'vision of mediocrity' (ie, set low expectations; 5 studies). ${ }^{24} 43484956$ Trouble identifying with the organisation's mission demotivated staff, as noted in 1 study: 'financial gain did not (supply purpose), the implication for...leaders...is that the perception of economic viability as an end-all may be counterproductive'. ${ }^{25}$

\section{System shocks}

System shocks-or an organisation-wide event that detracts from day-to-day operations-represented an inductively derived domain from 12

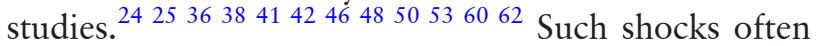
occurred as the result of planned institutional change, such as when organisations implemented a new electronic health record (4 studies) ${ }^{36385062}$ or underwent restructuring (4 studies). ${ }^{36} 465062$ However, shocks were also due to unplanned events, such as unanticipated leadership turnover (8 studies), ${ }^{2425414650536062}$ imminent financial failure (4 studies) 38424850 or scandals (1 study). ${ }^{50}$ When these events occurred, they overwhelmed the organisation's energy and resources and became the dominating concern (eg, 'We found that widespread concerns about finances...eclipsed attention paid to patient safety'). ${ }^{64}$ Shocks often negatively affected other domains (eg, 'An explosive level of turnover made connectivity almost impossible'; ${ }^{25}$ 'Sporadic involvement of senior management was common...in part because of frequent turnover'). ${ }^{24}$

Notably, some system shocks were transient, or a consequence of attempts to improve, as noted in accountable care organisations trying to improve cost and quality: 'changes aimed at improving established organisations often caused an initial decrement in their performance as a result of the substantial reorganisations'. ${ }^{36}$ Regardless of the cause, the effects of system shocks were reported to linger: '(Struggling) organisations (had) fragmented systems of accountability...a legacy of recent mergers'. ${ }^{46}$

\section{Dysfunctional external relations}

Seven studies ${ }^{24}$ 35-37465061 highlighted how dysfunctional external relationships with other healthcare facilities (5 studies), ${ }^{2435-3761}$ stakeholders (4 studies) ${ }^{37465061}$ or governing bodies (2 studies) ${ }^{37} 50$ were associated with dire consequences. Notably, community and patient engagement by low-performing facilities was also limited (3 studies). ${ }^{374661}$ Failure in this domain was prominent in facilities where financial performance was dependent on external collaboration: 'In one (accountable care organization)...local hospitals viewed the group as a threat and refused to cooperate in providing patient information'. ${ }^{36}$ 
Table 1 Domains characterising struggling healthcare organisations

\begin{tabular}{|c|c|c|c|}
\hline $\begin{array}{l}\text { Domain } \\
\text { theme }\end{array}$ & $\begin{array}{l}\text { Definition } \\
\text { representative quotes }\end{array}$ & $\begin{array}{l}\text { Supporting* } \\
\text { studies, } n=30\end{array}$ & $\begin{array}{l}\text { Contradicting* } \\
\text { studies, } \mathrm{n}=30\end{array}$ \\
\hline $\begin{array}{l}\text { Poor organisational } \\
\text { culture }\end{array}$ & 'Norms, values and basic assumptions of a given organisation.' & $30(100 \%)$ & $14(47 \%)$ \\
\hline $\begin{array}{l}\text { Limited involvement } \\
\text { and ownership }\end{array}$ & $\begin{array}{l}\text { 1. In contrast, 'low' performing organisations were generally characterised by confused } \\
\text { and fragmented systems of accountability... senior managers only intervened in } \\
\text { exceptional circumstances. }{ }^{46}\end{array}$ & $27(90 \%)$ & $8(27 \%)$ \\
\hline Not collaborative & $\begin{array}{l}\text { 2. The lack of staff-to-staff connectivity translated into poor resident care. For example, } \\
\text { one resident went without care during an 8-hour shift because the two (CNAs) assigned } \\
\text { to that unit each thought the other was taking care of the resident. }\end{array}$ & $21(70 \%)$ & $4(13 \%)$ \\
\hline Hierarchical & $\begin{array}{l}\text { 3. 'Why is considered a bad word here. They don't want to share the power. If you do, } \\
\text { you get shot down. It's that hierarchical thing. }{ }^{25}\end{array}$ & $17(57 \%)$ & $4(13 \%)$ \\
\hline $\begin{array}{l}\text { Disconnected } \\
\text { leadership }\end{array}$ & $\begin{array}{l}\text { 4. 'I would say minimal, minimal. They had some problems with the previous CEO. And } \\
\text { after that there was an interim guy that I met just once. }{ }^{41}\end{array}$ & $16(53 \%)$ & $2(7 \%)$ \\
\hline Inadequate infrastructure & $\begin{array}{l}\text { Inadequate staffing (recruitment and retention) or resources, including poor } \\
\text { technological or quality improvement infrastructure. }\end{array}$ & $27(90 \%)$ & $18(60 \%)$ \\
\hline $\begin{array}{l}\text { Minimal quality } \\
\text { improvement systems }\end{array}$ & $\begin{array}{l}\text { 5. Participants at low-performing hospitals described minimal or very recent use of } \\
\text { formal problem-solving tools, such as root-cause analysis, and variable interest in } \\
\text { data. }{ }^{24}\end{array}$ & $20(67 \%)$ & $10(33 \%)$ \\
\hline $\begin{array}{l}\text { Insufficient staffing and } \\
\text { high turnover }\end{array}$ & $\begin{array}{l}\text { 6. (Struggling hospitals) had more turnover among nursing staff, more frequent use } \\
\text { of per diem employees, and were more likely to have nurses (especially in the surgical } \\
\text { intensive care unit) with less formal training. }\end{array}$ & $18(60 \%)$ & $7(23 \%)$ \\
\hline $\begin{array}{l}\text { Underdeveloped } \\
\text { information technology }\end{array}$ & $\begin{array}{l}\text { 7. Information technology systems were a common theme, viewed as a key to success } \\
\text { across all hospitals, although successful implementation and support had only occurred } \\
\text { in the high performers. }{ }^{41}\end{array}$ & $17(57 \%)$ & $6(20 \%)$ \\
\hline Lack of resources & $\begin{array}{l}\text { 8. In contrast, lower-performing organisations struggled to have high-quality data } \\
\text { reports. Participants described that they lacked the resources needed to collect timely } \\
\text { and accurate data. }{ }^{37}\end{array}$ & $15(50 \%)$ & $4(13 \%)$ \\
\hline $\begin{array}{l}\text { Lack of cohesive mission } \\
\text { and vision }\end{array}$ & $\begin{array}{l}\text { Mission is poorly defined, contrary to other stated missions, externally motivated or sets } \\
\text { low expectations. }\end{array}$ & $21(70 \%)$ & $5(17 \%)$ \\
\hline Conflicting missions & $\begin{array}{l}\text { 9. The conflicting message regarding the organisational mission, that is, the explicit } \\
\text { (resident care) versus the implicit (economic viability and regulatory compliance), } \\
\text { fragmented and confused staff. }\end{array}$ & $12(40 \%)$ & $1(3 \%)$ \\
\hline $\begin{array}{l}\text { Externally motivated } \\
\text { vision }\end{array}$ & $\begin{array}{l}\text { 10. After Medicare readmissions penalties went into force, managers elevated the } \\
\text { priority of readmissions reduction but without the emphasis on readmissions being } \\
\text { detrimental to patients themselves. } \text {.5 }^{5 .}\end{array}$ & $9(30 \%)$ & $4(13 \%)$ \\
\hline Poorly defined goals & $\begin{array}{l}\text { 11. Goal definition distinguished higher-performing hospitals... We found that aiming } \\
\text { for general improvement seemed far less motivating than aiming for an absolute } \\
\text { standard of zero (central line-associated blood stream infections). }{ }^{48}\end{array}$ & $6(20 \%)$ & $1(3 \%)$ \\
\hline Vision of mediocrity & $\begin{array}{l}\text { 12. In the high-uptake practices, an aspirational uptake target was more likely to be } \\
\text { reported than in the low-uptake practices. }{ }^{99}\end{array}$ & $5(17 \%)$ & 0 \\
\hline System shocks & An organisation-wide event or change that detracts from day-to-day operations & $12(40 \%)$ & $2(7 \%)$ \\
\hline $\begin{array}{l}\text { C-suite (or senior } \\
\text { leader) turnover }\end{array}$ & $\begin{array}{l}\text { 13. 'Over the last } 4 \text { years... we've had four or five CEOs so it's really been hard to figure } \\
\text { out a pattern of leadership.'.1 }\end{array}$ & $8(27 \%)$ & 0 \\
\hline $\begin{array}{l}\text { Financial failure or } \\
\text { severe difficulties }\end{array}$ & $\begin{array}{l}\text { 14. Interviewees in another lower-performing practice pointed out difficulties } \\
\text { in improving systems and achieving buy-in when a parent system absorbed the } \\
\text { supplemental payments. }\end{array}$ & $4(13 \%)$ & 0 \\
\hline $\begin{array}{l}\text { Mergers (or } \\
\text { reorganisation) }\end{array}$ & $\begin{array}{l}\text { 15. A mixture of two different organisational cultures, after merging..., was another } \\
\text { issue that had a negative impact on the Trust. It was stated that there was inhouse } \\
\text { fighting because one hospital's staff thought they were better than the other... One } \\
\text { interviewee likened the situation to the 'Berlin Wall'. }{ }^{46}\end{array}$ & $4(13 \%)$ & 0 \\
\hline New EHR & $\begin{array}{l}\text { 16....only one of the higher-performing practices installed a new EHR in the midst of } \\
\text { medical home implementation, whereas three of the five lower-performing practices } \\
\text { did... } 38\end{array}$ & $4(13 \%)$ & $2(7 \%)$ \\
\hline Major scandals & $\begin{array}{l}\text { 17. In addition, there was poor public and press image...owing to the waiting list } \\
\text { irregularities. }{ }^{46^{6}}\end{array}$ & $1(3 \%)$ & 0 \\
\hline $\begin{array}{l}\text { Dysfunctional external } \\
\text { relations }\end{array}$ & $\begin{array}{l}\text { Organisations had poor relationships with key stakeholders or governing bodies, or } \\
\text { lacked well-functioning systems for collaboration with other healthcare facilities. }\end{array}$ & $7(23 \%)$ & $2(7 \%)$ \\
\hline Limited collaboration & $\begin{array}{l}\text { 18. Although low-performing hospitals mentioned collaboration with postacute } \\
\text { providers, the relationships were described as less well-developed.5. }\end{array}$ & $5(17 \%)$ & $2(7 \%)$ \\
\hline
\end{tabular}


Table 1 Continued

\begin{tabular}{|c|c|c|c|}
\hline $\begin{array}{l}\text { Domain } \\
\text { theme }\end{array}$ & $\begin{array}{l}\text { Definition } \\
\text { representative quotes }\end{array}$ & $\begin{array}{l}\text { Supporting* } \\
\text { studies, } n=30\end{array}$ & $\begin{array}{l}\text { Contradicting* } \\
\text { studies, } \mathrm{n}=30\end{array}$ \\
\hline $\begin{array}{l}\text { Antagonism with } \\
\text { stakeholders }\end{array}$ & $\begin{array}{l}\text { 19. Poorly performing Trusts were generally characterised by a history of poor } \\
\text { relationships with other key stakeholders and organisations... } 46\end{array}$ & $4(13 \%)$ & 0 \\
\hline $\begin{array}{l}\text { Strained relationship } \\
\text { with governing body }\end{array}$ & $\begin{array}{l}\text { 20. In contrast, relationships between the (local) level and higher zonal and regional } \\
\text { levels were described as distant, with little contact between focal persons working at } \\
\text { each of the administrative levels. }{ }^{37}\end{array}$ & $2(7 \%)$ & 0 \\
\hline
\end{tabular}

*Studies may have evidence that both supported and contradicted themes.

Primary quotes from interviewees are shown in quotations. Abstracted summary quotes and interpretations by authors are shown without quotations. CEO, chief executive officer; CNA, certified nursing assistant; EHR, electronic health record.

Domain prevalence by how performance was defined Although many domains were applicable to all struggling healthcare organisations, some differences were observed based on how performance was defined. For example, organisations struggling on a single disease (eg, CLABSI) noted difficulties with infrastructureparticularly QI infrastructure (10/14 studies)-more than external relations (1/14 studies). Healthcare organisations struggling on composite metrics-such as postoperative complications-were more concerned about their mission (10/12 studies) than other organisations (11/18 studies). For organisations struggling on overall performance (eg, star ratings), system shocks and dysfunctional external relationships were defining domains (3/4 and 4/4 studies, respectively; figure 2).

\section{Quality assessment}

Study quality was moderate-high with 6 studies scoring 9/1025 40 48 515357 (online supplementary tables 2 and 3). Most studies were rated as 'valuable' (19 studies). ${ }^{24} 253538414649-515355-63$ Only 6 studies considered the relationship between researchers and participants (CASP question 6). ${ }^{425} 40426163$ Studies with higher quality (score $\geq 9$ ) contributed more data (average 3 domains, 8 themes, 42 references) than lower-quality (score $\leq 6$ ) studies (average 3 domains, 7 themes, 21 references).

\section{DISCUSSION}

In this systematic review of 30 international studies, we found 5 distinct domains typified struggling healthcare organisations: (1) Poor organisational culture, (2) Inadequate infrastructure, (3) Lack of a cohesive mission and vision, (4) System shocks and (5) Dysfunctional external relations. Organisations often struggled in multiple domains simultaneously and nearly half of studies reported a recent system shock which appeared to worsen difficulties in other domains. While most domains had a clear, negative effect on organisations, infrastructure was not always linked to outcomes. Taken together, these domains represent a starting place to evaluate and diagnose low performance.

Many characteristics shared by struggling organisations were counter to characteristics associated with high-performing organisations. For example, while disconnected leaders and non-collaborative environments were frequently found in struggling organisations, engaged leadership and a collaborative organisational culture are associated with high performance. ${ }^{12-16}$ Furthermore, a 'flat' or team-based approach to problems is often associated with high performance, ${ }^{12-16}$ whereas we found hierarchical culture described in 17 studies of struggling organisations. Employees at struggling organisations also described poor self-efficacy and often perseverated on patient factors (eg, 'difficult patients') as barriers that could not be overcome, rather than being motivatedas high performers often are-to facilitate communication or provide additional resources to patients most in need. This view of patients as barriers was linked to a general sense that leadership at struggling organisations was motivated by penalties and finances, rather than by a patient-centred mission, which is associated with improved patient experience, physician satisfaction and quality of care ${ }^{6-68}$ Finally, struggling hospitals had antagonistic external relationships and poor IT infrastructure, whereas positive external, community and patient relationships, and well-integrated IT systems are associated with improved healthcare organisation performance. ${ }^{15164669}$

Not all themes readily contrasted with high performers. While most struggling hospitals reported poor infrastructure, this complaint was not unique to struggling organisations. Rather, employees believed they could benefit from additional staff and resources, regardless of performance or resource availability. Although it was not possible to assess differences in resource availability in low-performing versus high-performing organisations, 3 studies noted that there were no significant differences in performance based on resources. ${ }^{34} 6061$ Additionally, improving infrastructure in struggling hospitals did not appear to guarantee improved performance. One explanation offered was that efforts to improve infrastructure frequently diverted resources and disrupted existing care pathways, thus causing a decrement in performance (or leading to a system shock) for the short term.

'System shocks' was a domain unique to struggling organisations. Although not all change necessarily 
causes disruption, being unprepared or unrealistic about the effort required can demotivate and anger staff. ${ }^{70}$ It is also possible that struggling organisations had underlying problems with disconnected leadership or poor organisational culture that led staff to be less tolerant and responsive to change. ${ }^{11-16}$ These underlying factors may be further exacerbated when system shocks occur, overwhelming struggling organisations and causing difficulties in other domains. As noted previously, many system shocks were caused by efforts to improve care in the long term and thus may not be completely avoidable. To prevent disastrous consequences, shocks must be anticipated and addressed. When shocks cannot be anticipated, leaders may directly address shocks to reduce negative consequences and potentially create positive change. Examples of using disruptive events as the impetus for culture change abound in business, with examples such as Delta Airlines, Ecolab and Novartis, who all used financial difficulties or scandals to improve their companies. ${ }^{71}$ Parallel possibilities in healthcare can be found in the dramatic organisational changes that may follow sentinel events. ${ }^{72} 73$

How may these domains inform efforts to improve quality of care? One approach may be to diagnose which domain(s) is the problem. This may be difficult for organisations, as measurement requires understanding employee perceptions and not all domains have validated measures. Furthermore, many of these domains are interlinked and may be hard to disentangle. ${ }^{745}$ Although multiple tools exist for evaluating organisational or patient-safety culture (eg, Hospital Survey on Patient Safety Culture), use of differing instruments with varying validity make longitudinal assessments and comparisons between hospitals difficult. $^{7475}$ Given these difficulties, using the identified domains to facilitate conversation with front-line staff may be the first step.

After diagnosis, comes intervention. Although no easy fix exists for any domain, some studies may guide improvement. For example, a recent study of 10 US hospitals demonstrated that a multimodal intervention that involved creating 'guiding coalitions' (multidisciplinary intervention team) improved both organisational culture and outcomes. ${ }^{7677}$ Similarly, to reduce CLABSI, empowering nurses to speak up when providers break sterility is important. ${ }^{78}$ Even within hierarchical cultures, empowerment can be improved by using checklists, ensuring supervisory support, and framing instances of nurses speaking up as patient safety issues rather than power or political ones. ${ }^{78}$ For struggling organisations, these small changes may be both easier to perform and more sustainable, potentially leading to culture change over time. ${ }^{79} 80$ To address concerns over organisational motivation, struggling facilities may have more success if they recognise that nurses may view the extra burden of improvement as financially motivated, and reframe in terms of benefit to patients. ${ }^{81}{ }^{82}$ Struggling organisations that are poorly networked could begin to improve relations by, for example, joining a quality collaborative-providing access to shared expertise and QI infrastructure and promoting positive culture change. ${ }^{65} 83-85$ Finally, to capitalise on the opportunity provided by a system shock, hospital leadership may prepare for change by centering on a salient mission to galvanise employees. For example, during and after mergers, leadership must unify to prevent an 'us vs them' mentality that can destroy collaboration and morale. ${ }^{86}$ During financial difficulties, leadership must be transparent regarding budgeting decisions. For example, one hospital turned around their financial crisis through transparency, using town halls to discuss financial problems and brainstorm solutions. In response, senior physicians united and donated money to prevent staff lay-offs. ${ }^{87}$

Our study has strengths. It is among the first to summarise and codify organisation features that characterise struggling healthcare organisations. Use of framework-based thematic synthesis allowed us to apply a combination of inductive and deductive reasoning to generate novel domains that align with conceptual frameworks and identify ways to improve status quo. In addition, we synthesised our findings into 5 concrete, potentially measurable and modifiable domains, thus enabling organisations to identify barriers to inform future improvement. We followed a rigorous approach including an explicit, published protocol, a comprehensive literature search, and review and qualitative coding by three reviewers. Finally, we unearthed an important domain-system shocksand identify how it may create critical, system-wide barriers for improvement.

Our study also has limitations. First, qualitative studies by nature have a small sample size with limited number of individuals and scenarios. However, qualitative data provide greater depth and detail to understand underlying issues in context-which was our goal. Second, to avoid making incorrect assumptions, we reported language used by interviewees even if inconsistent with organisational science literature. Third, as with all systematic reviews, we were only able to assess reported results and quotations. Fourth, the quality of included studies varied and methodological stuy details were often lacking, reducing our ability to evaluate quality. Finally, whether these domains cause-or result from-organisational struggle, cannot be determined from this work. Rather than infer causality, we focused on identifying characteristics of struggling organisations that may reflect barriers to improvement.

Our study has important implications. First, our findings suggest that health systems preparing for large-scale organisational change should adequately prepare in order to prevent system shocks, which, counterintuitively, may impede change. Second, our 
study underscores the importance of context, organisational climate and related factors in determining hospital performance. Third, we continue to require validated methods of measuring and improving organisational domains, such as those found in this study. In the interim, leaders should engage front-line staff to help identify and address problem domains.

Healthcare value and quality matter now more than ever. We found struggling healthcare organisations have unique characteristics that may hinder their ability to meet quality challenges. The domains delineated in this review provide a starting point for addressing performance. The next step is to design high-quality interventions that help struggling hospitals improve.

\author{
Author affiliations \\ ${ }^{1}$ Department of Internal Medicine, University of Michigan Medical School, Ann \\ Arbor, Michigan, USA \\ ${ }^{2}$ Center for Clinical Management Research, Veterans Affairs Ann Arbor \\ Healthcare System, Ann Arbor, Michigan, USA \\ ${ }^{3}$ Patient Safety Enhancement Program, Ann Arbor Veterans Affairs Medical \\ Center/University of Michigan, Ann Arbor, Michigan, USA \\ ${ }^{4}$ Departmentof Pediatrics and Communicable Diseases, University of Michigan \\ Medical School, Ann Arbor, Michigan, USA \\ ${ }^{5}$ Taubman Health Sciences Library, University of Michigan, Ann Arbor, Michigan, \\ USA
}

Contributors As first author of this study, I take responsibility for the integrity of this work as a whole. We certify that all authors have seen and approved the manuscript. Each author has contributed significantly to it.

Funding This study was supported by Centers for Disease Control and Prevention (Contract Number: 200-2015-88275).

Disclaimer The findings and conclusions in this manuscript are those of the authors and do not necessarily represent the official position of the Centers for Disease Control and Prevention or the Department of Veterans Affairs.

Competing interests SS has received fees for serving on advisory boards for Doximity and Jvion. JM has received honoraria for lectures and teaching related to prevention and value-based purchasing policies involving catheter-associated urinary tract infection and hospital-acquired pressure ulcers. She has also received honoraria from RAND Corporation/ AHRQ for preparation of an AHRQ Chapter update on prevention of catheter-associated UTI.

Patient consent Not required.

Provenance and peer review Not commissioned; externally peer reviewed.

Data sharing statement Coding data from this qualitative review are available upon request to the corresponding author, VMV, atvalmv@umich.edu.

Open access This is an open access article distributed in accordance with the Creative Commons Attribution Non Commercial (CC BY-NC 4.0) license, which permits others to distribute, remix, adapt, build upon this work noncommercially, and license their derivative works on different terms, provided the original work is properly cited, appropriate credit is given, any changes made indicated, and the use is noncommercial. See: http://creativecommons.org/licenses/by-nc/4. $0 /$.

\section{REFERENCES}

1 Institute of Medicine Committee on Quality of Health Care in A. Crossing the quality chasm: a new health system for the 21 st Century. Washington DC: National Academies Press, 2001.
2 McGlynn EA, Asch SM, Adams J, et al. The quality of health care delivered to adults in the United States. N Engl J Med 2003;348:2635-45.

3 Suter LG, Li SX, Grady JN, et al. National patterns of risk-standardized mortality and readmission after hospitalization for acute myocardial infarction, heart failure, and pneumonia: update on publicly reported outcomes measures based on the 2013 release. J Gen Intern Med 2014;29:1333-40.

4 Wakeam E, Hevelone ND, Maine R, et al. Failure to rescue in safety-net hospitals: availability of hospital resources and differences in performance. JAMA Surg 2014;149:229-35.

5 Allison JJ, Kiefe CI, Weissman NW, et al. Relationship of hospital teaching status with quality of care and mortality for Medicare patients with acute MI. JAMA 2000;284:1256-62.

6 Pines JM, Localio AR, Hollander JE, et al. The impact of emergency department crowding measures on time to antibiotics for patients with community-acquired pneumonia. Ann Emerg Med 2007;50:510-16.

7 Jha AK, Orav EJ, Epstein AM. Low-quality, high-cost hospitals, mainly in South, care for sharply higher shares of elderly black, Hispanic, and medicaid patients. Health Aff 2011;30:1904-11.

8 Joynt KE, Orav EJ, Jha AK. Mortality rates for Medicare beneficiaries admitted to critical access and non-critical access hospitals, 2002-2010. JAMA 2013;309:1379-87.

9 Damschroder LJ, Aron DC, Keith RE, et al. Fostering implementation of health services research findings into practice: a consolidated framework for advancing implementation science. Implement Sci 2009;4:50.

10 Braithwaite J, Herkes J, Ludlow K, et al. Association between organisational and workplace cultures, and patient outcomes: systematic review. BMJ Open 2017;7.

11 Weiner BJ. A theory of organizational readiness for change. Implement Sci 2009;4:67.

12 Krein SL, Damschroder LJ, Kowalski CP, et al. The influence of organizational context on quality improvement and patient safety efforts in infection prevention: a multi-center qualitative study. Soc Sci Med 2010;71:1692-701.

13 Weaver SJ, Weeks K, Pham JC, et al. On the CUSP: Stop BSI: evaluating the relationship between central line-associated bloodstream infection rate and patient safety climate profile. Am J Infect Control 2014;42:S203-8.

14 Saint S, Kowalski CP, Banaszak-Holl J, et al. The importance of leadership in preventing healthcare-associated infection: results of a multisite qualitative study. Infect Control Hosp Epidemiol 2010;31:901-7.

15 Zingg W, Holmes A, Dettenkofer M, et al. Hospital organisation, management, and structure for prevention of health-care-associated infection: a systematic review and expert consensus. Lancet Infect Dis 2015;15:212-24.

16 Taylor N, Clay-Williams R, Hogden E, et al. High performing hospitals: a qualitative systematic review of associated factors and practical strategies for improvement. BMC Health Serv Res 2015;15:244.

17 Forman J, Creswell JW, Damschroder L, et al. Qualitative research methods: key features and insights gained from use in infection prevention research. Am J Infect Control 2008;36:764-71.

18 Dixon-Woods M. Using framework-based synthesis for conducting reviews of qualitative studies. BMC Med 2011;9:39.

19 Carroll C, Booth A, Cooper K. A worked example of "best fit" framework synthesis: a systematic review of views concerning 
the taking of some potential chemopreventive agents. BMC Med Res Methodol 2011;11:29.

20 Moher D, Liberati A, Tetzlaff J, et al. Preferred reporting items for systematic reviews and meta-analyses: the PRISMA statement. J Clin Epidemiol 2009;62:1006-12.

21 Schneider B, Ehrhart MG, Macey WH. Organizational climate and culture. Annu Rev Psychol 2013;64:361-88.

22 Baxter R, Taylor N, Kellar I, et al. What methods are used to apply positive deviance within healthcare organisations? A systematic review. BMJ Qual Saf 2016;25:190-201.

23 Higgins J, Green S. Cochrane Handbook for Systematic Reviews of Interventions, Version 5.1.0. 2011 http://www. cochrane-handbook.org/ (accessed 2 Jul 2015).

24 Curry LA, Spatz E, Cherlin E, et al. What distinguishes topperforming hospitals in acute myocardial infarction mortality rates? A qualitative study. Ann Intern Med 2011;154:384-90.

25 Forbes-Thompson S, Leiker T, Bleich MR. High-performing and low-performing nursing homes: a view from complexity science. Health Care Manage Rev 2007;32:341-51.

26 Bergs J, Lambrechts F, Simons P, et al. Barriers and facilitators related to the implementation of surgical safety checklists: a systematic review of the qualitative evidence. BMJ Qual Saf 2015;24:776-86.

27 Thomas J, Harden A. Methods for the thematic synthesis of qualitative research in systematic reviews. BMC Med Res Methodol 2008;8:45.

28 Malterud K. Qualitative research: standards, challenges, and guidelines. Lancet 2001;358:483-8.

29 Verboom B, Montgomery P, Bennett S. What factors affect evidence-informed policymaking in public health? Protocol for a systematic review of qualitative evidence using thematic synthesis. Syst Rev 2016;5:61.

30 Creswell JW. Qualitative inquiry and research design: choosing among five approaches: SAGE Publications, 2012.

31 CASP Qualitative Research Checklist. 2017 http://www.caspuk.net/casp-tools-checklists (accessed 12 Jun 2017).

32 Hannes K. Chapter 4: Critical appraisal of qualitative research. In: Noyes JBA, Hannes K, Harden A, Harris J, Lewin S. eds. Supplementary guidance for inclusion of qualitative research in cochrane systematic reviews of interventions: cochrane collaboration qualitative methods group, 2011.

33 Dixon-Woods M, Bonas S, Booth A, et al. How can systematic reviews incorporate qualitative research? A critical perspective. Qual Res 2006;6:27-44.

34 Bickell NA, Moss AD, Castaldi M, et al. Organizational factors affect safety-net hospitals' breast cancer treatment rates. Health Serv Res 2017;52:2137-55.

35 Brewster AL, Cherlin EJ, Ndumele CD, et al. What works in readmissions reduction: how hospitals improve performance. Med Care 2016;54:600-7.

36 D'Aunno T, Broffman L, Sparer M, et al. Factors that distinguish high-performing accountable care organizations in the medicare shared savings program. Health Serv Res 2018;53:120-37.

37 Fetene N, Linnander E, Fekadu B, et al. The ethiopian health extension program and variation in health systems performance: what matters? PLoS One 2016;11.

38 Gabbay RA, Friedberg MW, Miller-Day M, et al. A positive deviance approach to understanding key features to improving diabetes care in the medical home. Ann Fam Med 2013;11 Suppl 1:S99-S107.
39 Gagliardi AR, Nathens AB. Exploring the characteristics of high-performing hospitals that influence trauma triage and transfer. J Trauma Acute Care Surg 2015;78:300-5.

40 Hafner JM, Williams SC, Morton DJ, et al. From bad to better: a qualitative assessment of low-performing hospitals that improved their smoking cessation counseling performance. J Clin Outcomes Manag 2008;15:329-37.

41 Hockey PM, Bates DW. Physicians' identification of factors associated with quality in high- and low-performing hospitals. Jt Comm J Qual Patient Saf 2010;36:217-23.

42 Hogg W, Baskerville N, Nykiforuk C, et al. Improved preventive care in family practices with outreach facilitation: understanding success and failure. J Health Serv Res Policy 2002;7:195-201.

43 Hysong SJ, Best RG, Pugh JA. Clinical practice guideline implementation strategy patterns in Veterans Affairs primary care clinics. Health Serv Res 2007;42:84-103.

44 Kirsh S, Hein M, Pogach L, et al. Improving outpatient diabetes care. Am J Med Qual 2012;27:233-40.

45 Landman AB, Spatz ES, Cherlin EJ, et al. Hospital collaboration with emergency medical services in the care of patients with acute myocardial infarction: perspectives from key hospital staff. Ann Emerg Med 2013;61:185-95.

46 Mannion R, Davies HT, Marshall MN. Cultural characteristics of "high" and "low" performing hospitals. J Health Organ Manag 2005;19:431-9.

47 McAlearney AS, Hefner JL. Getting to Zero: Goal Commitment to Reduce Blood Stream Infections. Med Care Res Rev 2016;73:458-77.

48 Scheck McAlearney A, Hefner JL, Robbins J, et al. Preventing central line-associated bloodstream infections: a qualitative study of management practices. Infect Control Hosp Epidemiol 2015;36:557-63.

49 Newby KV, Parsons J, Brooks J, et al. Identifying strategies to increase influenza vaccination in GP practices: a positive deviance approach. Fam Pract 2016;33:318-23.

50 Ravaghi H, Mannion R, Sajadi HS. Organizational Failure in an NHS Hospital Trust: A Qualitative Study. Health Care Manag 2015;34:367-75.

51 Rose AJ, Petrakis BA, Callahan P, et al. Organizational characteristics of high- and low-performing anticoagulation clinics in the Veterans Health Administration. Health Serv Res 2012;47:1541-60.

52 Scott-Cawiezell J, Main DS, Vojir CP, et al. Linking nursing home working conditions to organizational performance. Health Care Manage Rev 2005;30:372-80.

53 Shin MH, Sullivan JL, Rosen AK, et al. Examining the validity of AHRQ's patient safety indicators (PSIs): is variation in PSI composite score related to hospital organizational factors? Med Care Res Rev 2014;71:599-618.

54 Wakeam E, Hyder JA, Ashley SW, et al. Barriers and Strategies for Effective Patient Rescue: A Qualitative Study of Outliers. Jt Comm J Qual Patient Saf 2014;40:503-6.

55 Young GJ, Charns MP, Daley J, et al. Best practices for managing surgical services: the role of coordination. Health Care Manage Rev 1997;22:72-81.

56 Caris MG, Kamphuis PGA, Dekker M, et al. Patient Safety Culture and the Ability to Improve: A Proof of Concept Study on Hand Hygiene. Infect Control Hosp Epidemiol 2017;38:1277-83.

57 Chang AM, Cohen DJ, Lin A, et al. Hospital Strategies for Reducing Emergency Department Crowding: A MixedMethods Study. Ann Emerg Med 2018;71:25. 
58 Chuang E, Cabrera C, Mak S, et al. Primary care team- and clinic level factors affecting HPV vaccine uptake. Vaccine 2017;35:4540-7.

59 Ellerbe LS, Manfredi L, Gupta S, et al. VA residential substance use disorder treatment program providers' perceptions of facilitators and barriers to performance on pre-admission processes. Addict Sci Clin Pract 2017;12:10.

60 Engle RL, Tyler DA, Gormley KE, et al. Identifying barriers to culture change: a qualitative analysis of the obstacles to delivering resident-centered care. Psychol Serv 2017;14:316-26.

61 Mabuchi S, Sesan T, Bennett SC. Pathways to high and low performance: factors differentiating primary care facilities under performance-based financing in Nigeria. Health Policy Plan 2018;33:41-58.

62 Miller-Day M, Applequist J, Zabokrtsky K, et al. A tale of four practices: a comparative analysis of high and low performing patient-centered medical homes. J Health Organ Manag 2017;31:630-46.

63 Ralston SL, Atwood EC, Garber MD, et al. What works to reduce unnecessary care for bronchiolitis? A qualitative analysis of a national collaborative. Acad Pediatr 2017;17:198-204.

64 McAlearney AS, Hefner J, Robbins J, et al. Toward a highperformance management system in health care, part 4: Using high-performance work practices to prevent central lineassociated blood stream infections-a comparative case study. Health Care Manage Rev 2016;41:233-43.

65 Bradley EH, Brewster AL, McNatt Z, et al. How guiding coalitions promote positive culture change in hospitals: a longitudinal mixed methods interventional study. BMJ Qual Saf 2018;27:218-25.

66 Constand MK, MacDermid JC, Dal Bello-Haas V, et al. Scoping review of patient-centered care approaches in healthcare. BMC Health Serv Res 2014;14:271.

67 Wick EC, Galante DJ, Hobson DB, et al. Organizational culture changes result in improvement in patientcentered outcomes: implementation of an integrated recovery pathway for surgical patients. J Am Coll Surg 2015;221:669-77.

68 Nelson KM, Helfrich C, Sun H, et al. Implementation of the patient-centered medical home in the Veterans Health Administration: associations with patient satisfaction, quality of care, staff burnout, and hospital and emergency department use. JAMA Intern Med 2014;174:1350-8.

69 O'Mara-Eves A, Brunton G, Oliver S, et al. The effectiveness of community engagement in public health interventions for disadvantaged groups: a meta-analysis. BMC Public Health 2015; 15:129.

70 Scott JT, Rundall TG, Vogt TM, et al. Kaiser Permanente's experience of implementing an electronic medical record: a qualitative study. BMJ 2005;331:1313-6.
71 Jay W, Lorsch EM. Culture is not the culprit. Harv Bus Rev. Boston, MA: Harvard Buiness School Publishing Corporation, 2016.

72 Wachter RM. The digital doctor: hope, hype, and harm at the dawn of medicine's computer age. New York, NY: McGraw-Hill Education, 2015.

73 Pokharel K, Biswas BK, Tripathi M, et al. Missed central venous guide wires: a systematic analysis of published case reports. Crit Care Med 2015;43:1745-56.

74 Dixon-Woods M, Baker R, Charles K, et al. Culture and behaviour in the English National Health Service: overview of lessons from a large multimethod study. BMJ Qual Saf 2014;23:106-15.

75 Mannion R, Konteh FH, Davies HT. Assessing organisational culture for quality and safety improvement: a national survey of tools and tool use. Qual Saf Health Care 2009;18:153-6.

76 Curry LA, Brault MA, Linnander EL, et al. Influencing organisational culture to improve hospital performance in care of patients with acute myocardial infarction: a mixed-methods intervention study. BMJ Qual Saf 2018;27:207-17.

77 Curry LA, Linnander EL, Brewster AL, et al. Organizational culture change in U.S. hospitals: a mixed methods longitudinal intervention study. Implement Sci 2015;10:29.

78 Pronovost P. Interventions to decrease catheter-related bloodstream infections in the ICU: the Keystone Intensive Care Unit Project. Am J Infect Control 2008;36:S171.e1-S171.e5.

79 Lin DM, Weeks K, Bauer L, et al. Eradicating central lineassociated bloodstream infections statewide: the Hawaii experience. Am J Med Qual 2012;27:124-9.

80 Lin DM, Weeks K, Holzmueller CG, et al. Maintaining and sustaining the On the CUSP: stop BSI model in Hawaii. Jt Comm J Qual Patient Saf 2013;39:51-60.

81 Mody L, Greene MT, Meddings J, et al. A National implementation project to prevent catheter-associated urinary tract infection in nursing home residents. JAMA Intern Med 2017;177:1154-62.

82 Saint S, Greene MT, Krein SL, et al. A program to prevent catheter-associated urinary tract infection in acute care. $\mathrm{N} \mathrm{Engl}$ J Med 2016;374:2111-9.

83 Flanders SA, Greene MT, Grant P, et al. Hospital performance for pharmacologic venous thromboembolism prophylaxis and rate of venous thromboembolism : a cohort study. JAMA Intern Med 2014;174:1577-84.

84 Chopra V, Smith S, Swaminathan L, et al. Variations in peripherally inserted central catheter use and outcomes in michigan hospitals. JAMA Intern Med 2016;176:548-51.

85 Wells S, Tamir O, Gray J, et al. Are quality improvement collaboratives effective? A systematic review. BMJ Qual Saf 2018;27:226-40.

86 Fondrevay JJ. After a Merger, Don't Let "Us vs. Them" Thinking Ruin the Company: Harvard Business Review, 2018.

87 Katherine B. Is Transparency always the best policy? Harvard Business Review 2009. 